\title{
Effects of norepinephrine on colonic tight junction protein expression during heat stress
}

\author{
YAN LUO ${ }^{1,2^{*}}$, HUIMING MA ${ }^{1 *}$, SHIBO NIU $^{2}, \mathrm{XU} \mathrm{LI}^{2,3}$, LIHONG NIE $^{2}$ and GUANGHUA LI ${ }^{2}$ \\ ${ }^{1}$ Key Laboratory of Fertility Preservation and Maintenance of Ministry of Education; ${ }^{2}$ Institute of Basic Medical Sciences, \\ Ningxia Medical University, Yinchuan, Ningxia 750004; ${ }^{3}$ People's Hospital of Ningxia Hui Autonomous Region, \\ Yinchuan, Ningxia 750021, P.R China
}

Received August 12, 2020; Accepted January 19, 2021

DOI: $10.3892 /$ etm.2021.9865

\begin{abstract}
Stress induced by changes in the internal or external environment in humans and animals leads to intestinal epithelial damage, in a manner that is associated with impaired intestinal barrier function. However, the role of the stress hormone norepinephrine (NE) in impairments in barrier function remains poorly understood. In the present study, a rat heat-exposed model was used to observe changes in the tight junction proteins Occludin and zonula occludens-1 (ZO-1), in addition to those in protease-activated receptor 2 (PAR-2) and transient receptor potential ankyrin 1 channel (TRPA1) in colon. The levels of plasma NE were detected using an ELISA kit. Different concentrations of NE were used to culture the human colon cell line Caco-2 for 6 and $24 \mathrm{~h}$ to investigate the cell viability using Cell Counting Kit- 8 assay, whilst the expression levels of Occludin, ZO-1, PAR-2 and TRPA1 were examined using western blotting and immunofluorescence in Caco-2 cells and immunohistrochemistry in rat colon tissues. Although there was no clear histological damage to the rat colonic mucosa, there were decreased expression levels of tight junction proteins Occludin and ZO-1 after heat exposure. In addition, PAR-2 expression was increased by heat exposure. It was found that TRPA1 expression was concentrated to the luminal surface of the colon in the heat exposed group compared with that in the control group. After the administration of increasing concentrations of NE for $6 \mathrm{~h}$, treatment did not affect cell viability. Furthermore, after application of NE for $24 \mathrm{~h}$, cell viability gradually increased as the NE concentration was elevated from 10 to $100 \mu \mathrm{M}$. However, no significant increase in viability was observed when the cells were treated
\end{abstract}

Correspondence to: Professor Guanghua Li, Institute of Basic Medical Sciences, Ningxia Medical University, 1160 Shengli Street, Yinchuan, Ningxia 750004, P.R China

E-mail: ghlee0404@163.com

*Contributed equally

Key words: norepinephrine, tight junction protein, proteaseactivated receptor 2 , colon, heat stress with 120 and $160 \mu \mathrm{M}$ NE. Occludin expression was decreased when $10 \mu \mathrm{M}$ NE was applied for 6 or $24 \mathrm{~h}$. By contrast, $60 \mu \mathrm{M}$ NE significantly downregulated Occludin expression in the $6 \mathrm{~h}$ group, but caused an insignificant decrease in the $24 \mathrm{~h}$ group. It was found that ZO-1 expression was upregulated after treatment with $10 \mu \mathrm{M} \mathrm{NE}$ for $6 \mathrm{~h}$, whilst downregulation was observed after treatment with $10 \mu \mathrm{M}$ NE for $24 \mathrm{~h}$. PAR-2 protein expression was increased after application of NE for both 6 and $24 \mathrm{~h}$, but not after treatment with $60 \mu \mathrm{M} \mathrm{NE}$. In addition, TRPA 1 expression was not affected by the treatment of NE, but increased positive staining was observed on the luminal side of the mucosa, which appeared to be concentrated in the cells of the luminal side in the rat colon after heat exposure. Collectively, the present results suggested that expression of tight junction proteins Occludin and ZO-1, in addition to that of PAR-2, can be regulated by NE, which may contribute to impairments in barrier function observed during heat stress.

\section{Introduction}

Stress is a pivotal factor for inflammation and reactive oxygen species (ROS) production, which can in turn induce damage to the epithelial barrier $(1,2)$. Heat stress induced by continuous high ambient temperatures or strenuous exercise in humans and animals can also lead to epithelial damage in the digestive tract due to the induction of cellular stress responses (3-5). Damage to the intestinal barrier is an important cause of bacterial translocation, inflammation, sepsis and multiple organ dysfunction (3). In particular, tight junction proteins are important for the maintenance of intestinal barrier integrity. For instance, zonula occludens-1 (ZO-1) and Occludin can both enhance steady-state barrier function in primary cultured Sertoli cells (4). Occludin function appear to require the cytoplasmic $\mathrm{C}$ terminus, which is highly phosphorylated in tight junction-associated Occludin, which binds to ZO-1, ZO-2 and ZO-3 (5). Occludin or ZO-1 knockdown increases the leak pathway permeability in cultured epithelial monolayers (6). In addition, the expression pattern and intracellular localization of Occludin and ZO-1 can change under stress, ischemic or inflammation conditions $(1,7)$.

Protease-activated receptor 2 (PAR-2) is highly expressed in the gastrointestinal tract, which has dual effects on inflammation and serves a key role in visceral hypersensitivity (8). 
Expression levels of intestinal tight junction proteins are reduced following water-avoidance stress (9). Furthermore, PAR-2 expression and mast cells are elevated under acute or chronic restraint stress, which contributes to the impaired epithelial barrier function in the colon and esophagus $(10,11)$. It has also been reported previously that increased mast cell numbers and mucosal PAR2 expression in the colon is mediated by the release of corticotrophin-releasing factor (10). Subsequently, the activation of PAR2 disrupts tight junctions and increases barrier permeability through the activation of p38 MAPK (12). PAR2 activation can also compromise vascular endothelial barrier function by suppressing the expression of vascular endothelial (Ve)-cadherin (13).

Transient receptor potential ankyrin 1 channel (TRPA1) serves as a key sensor for temperature and is permeable to $\mathrm{Ca}^{2+}$ (14). In addition, TRPA1 can be activated by mustard oil, cinnamic acid, garlicin, oxidative stress products and inflammatory mediators, such as prostanoids $(15,16)$. TRPA1 is mainly expressed on sensory neurons, afferent nerve endings and some non-neuronal cells, including immune cells, where it is involved in the process of nociception and inflammatory responses (17). Although TRPA1 is sensitive to temperature, this differs among species. For instance, mouse TRPA1 has been implicated in noxious cold detection but was also identified as one of the prime noxious heat sensors (18). Moreover, human TRPA1, which was originally considered to be temperature-insensitive, is also capable of sensing both hot and cold, where it is suggested that an allosteric mechanism could account for the variability in TRPA1 temperature responsiveness (18). TRPA1 can also serve as a sensor of cellular stress and tissue damage (19). This channel has been found to be upregulated in various tumors and is associated with tumor proliferation and metastasis, as well as promoting ROS and chemotherapy tolerance through the $\mathrm{Ca}^{2+}$-dependent anti-apoptotic pathway (20). Hypoxia and ischemia are associated with oxidative stress, which can activate TRPA1 in cerebral artery endothelial cells, leading to vasodilation, thereby reducing ischemic damage (21). These previous findings suggest a protective role of TRPA1. However, TRPA1 can also induce stress-induced duodenal lesions in a water immersion restraint stress rat model by promoting the release of substance P (22).

Norepinephrine (NE) is a stress hormone that is elevated due to activation of the hypothalamic-pituitary-adrenal axis, the locus coeruleus (LC) and involves noradrenergic neurons, the sympathetic adrenal medulla and the renin-angiotensin-aldosterone system during stress (23). NE constricts the blood vessels to change blood distribution, which is important during heat stress (24). In addition, previous studies have reported the effect of $\mathrm{NE}$ in the regulation of barrier function. Degeneration of noradrenergic fibers from the LC causes tight-junction disorganization in the rat brain (25). Moreover, another previous study revealed that in the presence of $\mathrm{NE}$, some Campylobacter strains show increased invasion into T84 epithelial cells and induced a greater breakdown of tight junctions (26). However, whether NE can directly contribute to the regulation of barrier function remains poorly understood.

Therefore, the present study aimed to investigate the expression changes in tight junction proteins Occludin and ZO-1, in addition to PAR-2 and TRPA1, in the rat colon after heat stress. Additionally, the present study aimed to evaluate the effects of $\mathrm{NE}$ on the expression levels of these proteins in cultured Caco- 2 cells.

\section{Materials and methods}

Animals. A total of 14 male Sprague-Dawley rats (weight, $220 \pm 20$ g, age, 8 weeks) were randomly divided into control and heat exposure groups ( $n=7$ per group). Rats were provided with standard laboratory diet and tap water ad libitum. The experimental procedures were approved by the Animal Ethics Committee of the Ningxia Medical University and Use Committee (Yinchuan, China). After an adaptation period of 3 days, rats were acclimatized to heat exposure with increasing durations from $2 \mathrm{~h}$ (day 1), $6 \mathrm{~h}$ (day 2), $14 \mathrm{~h}$ (day 3) and $18 \mathrm{~h}$ (day 4) at a temperature of $32 \pm 0.1^{\circ} \mathrm{C}$ in a closed, temperature-controlled chamber with a relative humidity of $54 \pm 5 \%$, 12-h light/dark cycle. After a rest on day 5, the rats received continuous 24 -h heat exposure $\left(32^{\circ} \mathrm{C}\right)$ for 9 days. The rats in the control group were raised in normal conditions $\left(24 \pm 0.1^{\circ} \mathrm{C}\right.$, relative humidity of $54 \pm 5 \%, 12$-h light/dark cycle).

Tissue preparation. All animals were anesthetized with intraperitoneal injections of $2 \%$ sodium pentobarbital $(40 \mathrm{mg} / \mathrm{kg})$ and sacrificed by exsanguination immediately after the 9-day $32^{\circ} \mathrm{C}$ heat exposure procedure. After anesthesia, the rats exhibited no signs of peritonitis, pain or discomfort. The abdominal cavity was rapidly opened and the distal colon (1-cm from the rectum; length, $2-3 \mathrm{~cm}$ ) was carefully excised, which was then placed into modified cold Krebs' solution (120.6 mM NaCl, $5.9 \mathrm{mM} \mathrm{KCl}, 2.5 \mathrm{mM} \mathrm{CaCl}_{2}, 1.2 \mathrm{mM} \mathrm{KH}_{2} \mathrm{PO}_{4}, 1.2 \mathrm{mM} \mathrm{MgCl}_{2}$, $15.4 \mathrm{mM} \mathrm{NaHCO}_{3}$ and $11.5 \mathrm{mM}$ glucose) for rinsing. Part of the distal colon was fixed with $4 \%$ paraformaldehyde for $24 \mathrm{~h}$ at room temperature. Blood was collected from the inferior vena cava into a heparinized tube and centrifuged at $1,449 \mathrm{x} g$ for $10 \mathrm{~min}$ at $4^{\circ} \mathrm{C}$ to obtain plasma samples, which was then frozen at $-80^{\circ} \mathrm{C}$ to measure $\mathrm{NE}$ levels.

Hematoxylin and eosin (H\&E) staining. Full-thickness $(4 \mu \mathrm{m})$ paraffin-embedded sections of the distal colon from control and heat exposed rats were stained with $H \& E$ staining for the evaluation of histological structural change. Xylene followed by a descending ethanol gradient was used for deparaffinization. Hematoxylin and eosin staining were both performed at room temperature for $60-70 \mathrm{~min}$. 60-70 $\mathrm{min}$ refers to the total time of HE staining, from deparaffinization to the end. For just Hematoxylin and eosin staining need 10 minutes $(5 \mathrm{~min}$ for $\mathrm{H}$, and 5 min for E). Light microscopy was used for observation (Magnification, $\mathrm{x} 400$ ).

Immunohistochemistry staining. Expression levels of Occludin, ZO-1, TRPA1 and PAR-2 were examined in rat distal colon full-thickness paraffin-embedded sections $(4 \mu \mathrm{m})$. Briefly, the sections were washed three times in PBS after deparaffinization using the same protocol as that used for in H\&E staining aforementioned and incubated with $3 \%$ hydrogen peroxide for $10 \mathrm{~min}$ at room temperature to block the activity of endogenous peroxidase. EDTA buffer antigen retrieval was used for Occludin and ZO-1, whilst citrate buffer antigen retrieval was used for TRPA-1 and PAR-2. Microwave-treated antigen 
retrieval was used, microwave heating in EDTA or citrate buffer was performed for 15 min under high fire, following by another 10 -min heating after boiling. The sections were washed again with PBS and blocked with $10 \%$ normal goat non-immune serum (cat. no. C01-03001; BIOSS) for $30 \mathrm{~min}$ at room temperature, which was followed by incubation with primary antibodies against rabbit polyclonal anti-PAR-2 (1:250; cat. no. bs-1178R; BIOSS), rabbit monoclonal anti-Occludin (1:200; Abcam; cat. no. ab216327), rabbit polyclonal anti-ZO-1 (1:500; cat. no. bs-1329-R; BIOSS) and rabbit polyclonal anti-TRPA1 (1:1,000; cat. no. ab58844; Abcam) overnight at $4^{\circ} \mathrm{C}$. The slices were then stained using a two-step IHC detection reagent kit (cat. no. PV-9001; ZSGB-BIO; http://www.zsbio.com/product/PV-9001) according to manufacturer's protocol. DAB chromogenic kit (cat. no. ZLI-9018; ZSGB-BIO) was used for detection. Hematoxylin was used at room temperature for $5 \mathrm{~min}$ for counterstaining. Light microscopy was used to image the sections (magnification, x200).

ELISA. The plasma level of NE was determined using an ELISA kit (cat. no. EL-0047C; Elabscience) according to the manufacturer's protocol.

Cell culture. Caco-2 cells were used for detection of the cell permeability (27). Caco-2 cells were kindly gifted by Professor Jingxin Li (Cheeloo College of Medicine, Shangdong University, Jinan, China). The cells were cultured in DMEM (Gibco; Thermo Fisher Scientific, Inc.) supplemented with 10\% FBS (cat. no. FB35015; Clark Bio Office; https://www. clarkbio.com/index.php? $\mathrm{m}=$ Content $\& \mathrm{c}=$ Index $\& \mathrm{a}=$ show $\&$ cati $\mathrm{d}=9 \& \mathrm{id}=6), 100 \mathrm{U} / \mathrm{ml}$ penicillin and $100 \mu \mathrm{g} / \mathrm{ml}$ streptomycin (Beijing Solarbio Science \& Technology Co., Ltd.) at $37^{\circ} \mathrm{C}$ under a humidified atmosphere of $5 \% \mathrm{CO}_{2}$. Caco-2 cells were collected when they reached $70-80 \%$ confluence and cells from passages 2-15 were used for all subsequent experiments.

Cell viability detection using a Cell Counting Kit (CCK)- 8 assay. Relative viability of Caco- 2 cells after NE treatment was detected using a CCK-8 (cat. no. BB-4202-2; BestBio Science) assay. The kit was used according to the manufacturer's protocols. Briefly, Cells ( $5 \times 10^{3}$ cells/well) in $100 \mu \mathrm{l}$ medium were added into 96-well plates. After $12 \mathrm{~h}$, cells were cultured with NE (cat. no. S25926; Shanghai Yuanye Bio-Technology Co., Ltd. http://www.shyuanye.com/goods-S25926.html) at different final concentrations $(0,5,10,20,40,60$ and $80 \mu \mathrm{M})$ for $6 \mathrm{~h}$ and $(10,20,40,60,80,100,120$ and $160 \mu \mathrm{M}) 24 \mathrm{~h}$ at $37^{\circ} \mathrm{C}$. In total, $10 \mu \mathrm{CCK}-8$ solution was added to the $100 \mu \mathrm{l}$ culture medium per well and incubated at $37^{\circ} \mathrm{C}$ for $2 \mathrm{~h}$. The optical density (OD) was measured at $450 \mathrm{~nm}$ using a microplate spectrophotometer (1420 Victor3; Thermo Fisher Scientific, Inc.). Relative cell viability $(\%)=[(\mathrm{OD}$ of NE treatment group-OD of blank)/(OD of control group-OD of blank)] $\mathrm{x} 100 \%$. Viability was represented as the percentage of culture without NE that was set to $100 \%$.

Western blot analysis. The expression levels of proteins were determined by western blotting. Cells $\left(1 \times 10^{6}\right)$ were plated into $6-\mathrm{cm}$ dishes and cultured until reaching $80 \%$ confluence. Cells were then separated into the control group, NE-treated $6 \mathrm{~h}$ group and NE-treated $24 \mathrm{~h}$ group. After 6 and $24 \mathrm{~h}$ culture at $37^{\circ} \mathrm{C}$, cells were washed three times with cold PBS and collected. The cell samples were lysed in lysis buffer supplemented with $0.1 \%$ protease inhibitor, $1 \%$ phosphatase inhibitor and $1 \%$ PMSF for $30 \mathrm{~min}$ on the ice. All reagents were from the BCA whole protein extraction kit (cat. no. KGP250; Nanjing KeyGen Biotech Co., Ltd.). Samples were centrifuged at 13,684 x g for $5 \mathrm{~min}$ at $4^{\circ} \mathrm{C}$. Protein concentration in the lysate was measured using the bicinchoninic acid protein assay kit (cat. no. KGPBCA; Nanjing KeyGen Biotech Co., Ltd.). After boiling the samples with SDS sample buffer for $5 \mathrm{~min}$, equal amounts of protein $(40 \mu \mathrm{g})$ were separated by $10 \%$ SDS-PAGE (Nanjing KeyGen Biotech Co., Ltd) and were transferred onto PVDF membranes (EMD Millipore). The membranes were blocked for $2 \mathrm{~h}$ at room temperature with $5 \%$ non-fat dry milk diluted in PBS. The membranes were then incubated with primary antibodies against Occludin (1:1,000; cat. no. ab216327; Abcam), ZO-1 (1:500; cat. no. bs-1329-R; BIOSS), TRPA1 (1:1,000; cat. no. ab58844; Abcam) and PAR-2 (1:500; cat. no. bs-1178R; BIOSS) at $4^{\circ} \mathrm{C}$ overnight. $\beta$-actin was used as an internal loading control (1:1,000; cat. no. TA09; ZSGB-BIO; OriGene Technologies, Inc.). Following three washes with TBS-T (0.2\% Tween-20), membranes were then incubated with the horseradish peroxidase (HRP)-conjugated anti-rabbit IgG secondary antibody (1:5,000; cat. no. ZB2301; ZSGB-BIO; OriGene Technologies, Inc.) and anti-mouse IgG secondary antibody (1:5,000; cat. no. ZB2305; ZSGB-BIO; OriGene Technologies, Inc.) respectively for $1 \mathrm{~h}$ at room temperature. Immunoreactive bands were visualized using enhanced chemiluminescence detection reagents (Affinity Biosciences). Protein expression levels were analyzed using an ImageJ Imaging System (version 1.37; National Institutes of Health).

Immunofluorescence. Caco-2 cells were seeded into 24-well plates containing $15-\mathrm{mm}$ slides. The complete medium was replaced by fresh complete medium (fully-supplemented DMEM) before further treatment with $\mathrm{NE}$ at a final concentration of $10 \mu \mathrm{M}$. After incubation for 6 and $24 \mathrm{~h}$ at $37^{\circ} \mathrm{C}$, the cells were washed three times with cold PBS and fixed in ice-cold $4 \%$ paraformaldehyde at room temperature for $20 \mathrm{~min}$. After washing with cold PBS, the cells were blocked with 1\% BSA (cat. no. B1010; Biotopped; http://www. bjbiotopped.com/showinfo-20-98588-0.html) for $30 \mathrm{~min}$ at room temperature. The cells were then incubated with primary antibodies against PAR-2 (1:300; cat. no. bs-1178R; BIOSS), Occludin (1:100; cat. no. ab216327; Abcam), ZO-1 (1:300; cat. no. bs-1329-R; BIOSS) and TRPA1 (1:200; cat. no. ab58844; Abcam) at $4^{\circ} \mathrm{C}$ overnight, followed by incubation with FITC-conjugated goat-anti-rabbit secondary antibodies (1:50; cat. no. bs-0295G-FITC; BIOSS) for $1 \mathrm{~h}$ at room temperature in the dark after washing in cold PBS. The slices were sealed with mounting medium containing DAPI (cat. no. DZ0125; Beijing Leagene Biotech Co., Ltd.; https://www.leagene.com/Catalogue/DZ0125-DAPIrsfpj_

ID482.html). Images were captured using an Olympus fluorescence microscope (Olympus Corporation) and analyzed using Adobe Photoshop CS3 10.0.1 version (Adobe Systems, Inc.) at x400 magnification.

Statistical analysis. Data are presented as the mean \pm SD, where $\mathrm{n}$ refers to the number of animals or the number of duplicates. 


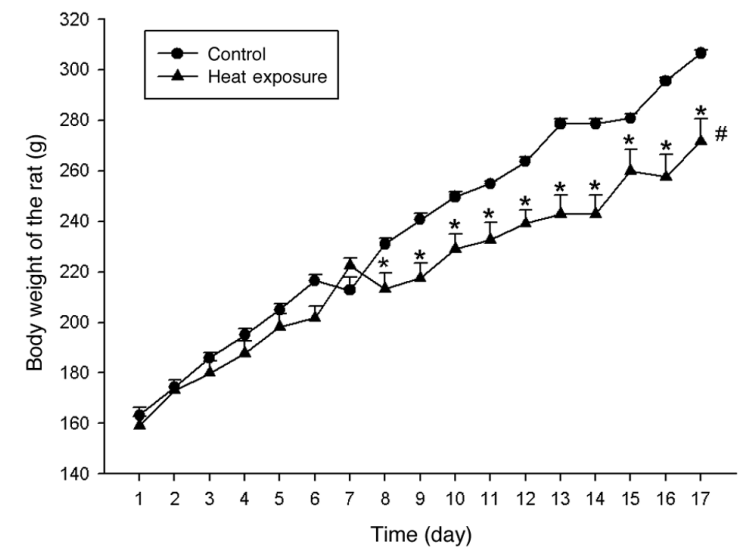

Figure 1. Changes in body weight following heat exposure. Body weight was significantly decreased in the heat exposure group. $\mathrm{n}=7$. ${ }^{*} \mathrm{P}<0.05$ vs. Control. \#, the body weight increase of the rats in the heat exposure groups was lower compared with that in the control group..

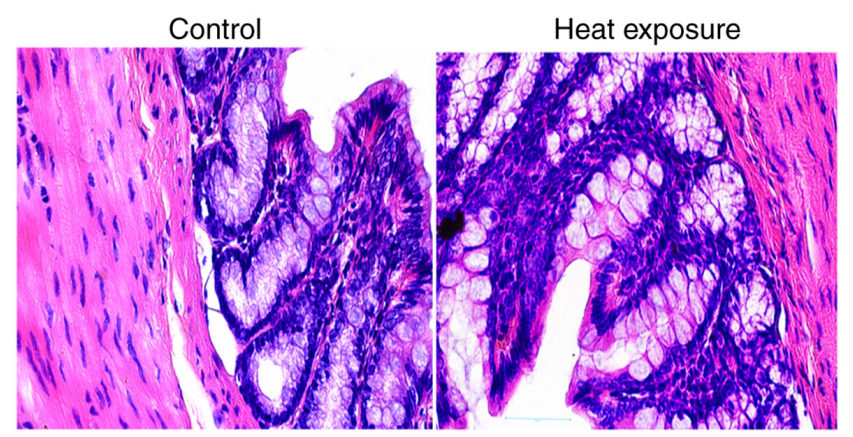

Figure 2. Representative photomicrographs of hematoxylin and eosin-stained sections (thickness, $4 \mu \mathrm{m}$ ) of the rat distal colon in control and heat exposure groups. Magnification, $\mathrm{x} 400$. There were no clear structural changes between control and heat exposure groups.

Unpaired Student's t-test was performed for comparisons between two groups and one-way ANOVA followed by Tukey's multiple comparisons test. Mixed two-way ANOVA followed by a Sidak corrections were used for comparisons among multiple groups with SigmaStat 3.5 software (Systat Software, Inc.). $\mathrm{P}<0.05$ was considered to indicate a statistically significant difference.

\section{Results}

Heat exposure animal model. All rats survived prior to sacrifice. According to the mixed two-way ANOVA (with animal treatment type as a between-subjects factor and time as the within-subjects factor) followed by post hoc testing with Sidak correction, the body weight increase of the rats in the heat exposure groups was lower compared with that in the control group $(\mathrm{F}=8.209, \mathrm{P}<0.05)$, whilst time also affected the weight of the rats $(\mathrm{F}=844.208 ; \mathrm{P}<0.001)$, with the difference more significant from day 8 onwards $(\mathrm{F}=28.15 ; \mathrm{P}<0.001)$ and weights in rats exposed to heat lower compared with those in rats in the control group (Fig. 1). This suggests that long lasting heat exposure adversely affected the rat weight.

According to the H\&E staining images, the mucosa in both control and heat-exposed rat colon tissues were found to be intact, with no notable structural changes (Fig. 2).

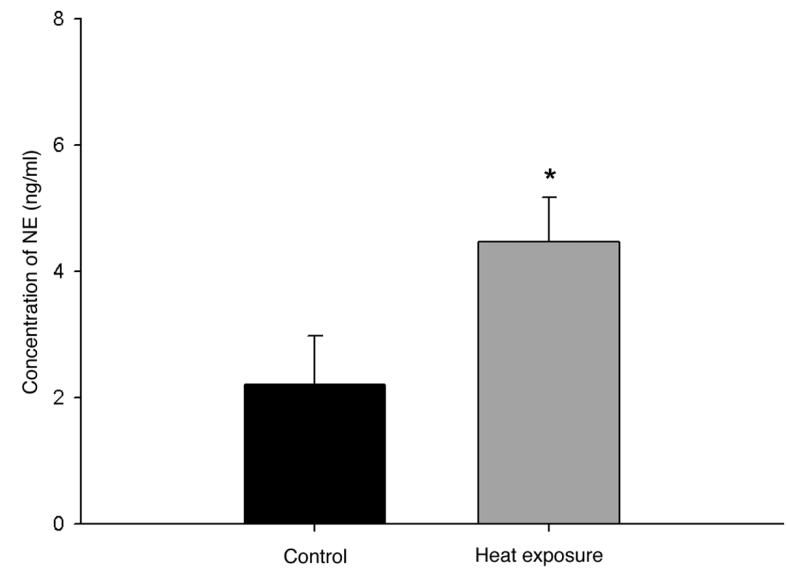

Figure 3. Plasma NE levels in control rats and rats following heat exposure. $\mathrm{n}=6 .{ }^{*} \mathrm{P}<0.05$ vs. Control. NE, norepinephrine.

The rats were treated for 9 days continuous 24-h heat exposure $\left(32^{\circ} \mathrm{C}\right)$ after 5 days of acclimatization. Plasma samples were collected on day 17 and the plasma NE level was detected. In the heat exposure group, the average plasma NE level was significantly elevated compared with that in the control group $(\mathrm{P}<0.05 ; \mathrm{n}=6$; Fig. 3).

Expression levels of Occludin, ZO-1, PAR-2 and TRPA1 in rat distal colon. In the control group, strong positive staining of Occludin was observed in the mucosa, which was mainly located on the cell membranes of epithelial cells and was decreased after heat exposure (Fig. 4A). ZO-1 was observed in the mucosa and smooth muscle cells, the expression of which was found to be attenuated in the heat exposure group in comparison with that in the control group (Fig. 4A). PAR-2 staining was detected in the mucosa and the myenteric nerve plexus, in addition to within smooth muscles cells (Fig. 4B). It was found that heat exposure increased PAR-2 expression, where a weaker expression was observed in the smooth muscle layer (Fig. 4B). Additionally, TRPA1 staining was identified in the epithelial cells of the colon mucosa and myenteric nerve plexus (Fig. 4B). After heat exposure, the expression pattern of TRPA1 in mucosal epithelial cells was different compared with that in control, with enhanced expression observed in the myenteric nerve plexus. Furthermore, increased positive staining was observed in the luminal side of the mucosa, which appeared to be concentrated in the cells of the luminal side (Fig. 4B).

Cell viability detection using a CCK-8 assay. Caco-2 cells were treated with different concentrations of NE for 6 and $24 \mathrm{~h}$, respectively. Treatment with increasing concentrations of NE for $6 \mathrm{~h}$ did not affect cell viability (Fig. 5A). However, the cell viability gradually increased as the NE concentration elevated from 10 to $100 \mu \mathrm{M}$ in the $24 \mathrm{~h}$ group, but there was no statistical difference when cells were treated with 120 and $160 \mu \mathrm{M}$ NE compared with that in control (Fig. 5B).

Protein expression levels of Occludin,ZO-1,TRPA1 and PAR-2 after the administration of $N E$. To examine the regulatory effect of NE on the expression levels of tight junction proteins, as well as PAR-2 and TRPA1, 10, 60 and $120 \mu \mathrm{M}$ were selected 

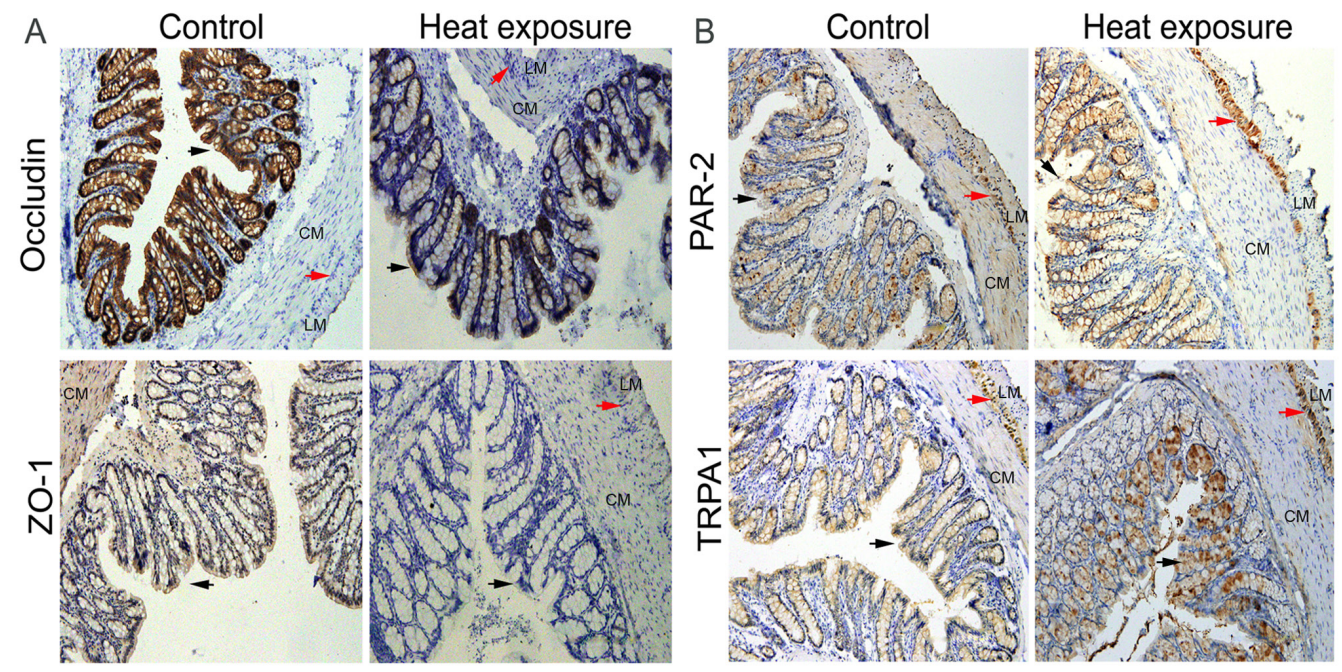

Figure 4. Expression levels of Occludin, ZO-1, TRPA1 and PAR-2 in the rat distal colon tissue sections in control and heat exposure groups. The figures (A, B) shown are representative of three different animals. Magnification, x200. Black arrows indicate the musca. Red arrows indicate the myenteric plexus. ZO-1, zonula occludens-1; PAR-2, protease-activated receptor 2; TRPA1, transient receptor potential ankyrin 1 channel; CM, circular muscle; LM, longitudinal muscle.

A

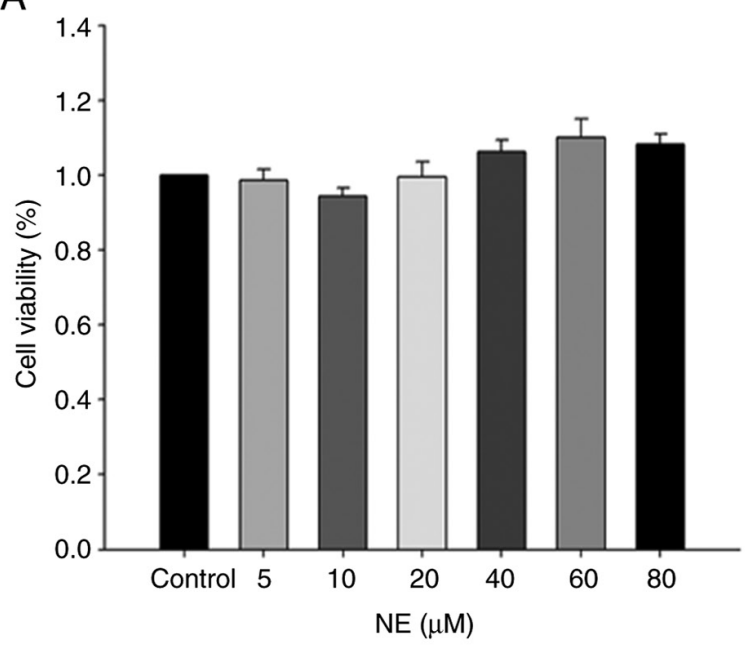

B

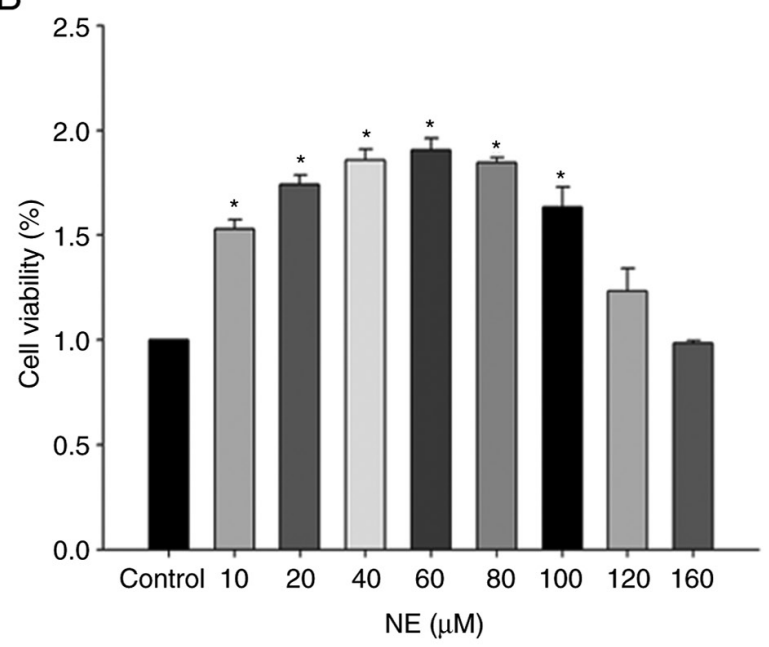

Figure 5. Influence of NE on relative Caco-2 cell viability. The relative viability of Caco-2 cells treated with different concentrations of NE for (A) 6 or (B) 24 h. ${ }^{*} \mathrm{P}<0.05$ vs. Control. NE, norepinephrine.

as the final NE concentration to stimulate Caco-2 cells for 6 and $24 \mathrm{~h}$. In the $6 \mathrm{~h}$ treatment group, Occludin expression was significantly decreased when 10 and $60 \mu \mathrm{M} \mathrm{NE}$ were applied compared with that in control $(\mathrm{n}=4 ; \mathrm{P}<0.05$; Fig. $6 \mathrm{~A}$ and $\mathrm{B})$. After $24 \mathrm{~h}$ treatment, $10 \mu \mathrm{M} \mathrm{NE}$ also significantly downregulated Occludin expression compared with that in control $(\mathrm{n}=4$; $\mathrm{P}<0.05$; Fig. 6A and B). Although administration of $60 \mu \mathrm{M}$ $\mathrm{NE}$ also decreased Occludin expression in the $24 \mathrm{~h}$ group, the difference was not statistically significant (Fig. 6A and B). Occludin expression was not significantly affected by treatment with $120 \mu \mathrm{M}$ NE for $6 \mathrm{~h}, 120 \mu \mathrm{M}$ NE appeared to have reduced Occludin expression after $24 \mathrm{~h}$, however, there was no significant difference (Fig. 6A and B). Significant upregulation of ZO-1 expression was observed after administration of $10 \mu \mathrm{M} \mathrm{NE}$ for $6 \mathrm{~h}$ compared with that in the control group $(\mathrm{n}=4 ; \mathrm{P}<0.05)$, but its expression was downregulated by $10 \mu \mathrm{M}$ $\mathrm{NE}$ after $24 \mathrm{~h}$ treatment compared with that in the control group $(\mathrm{P}<0.05 ; \mathrm{n}=4$; Fig. $6 \mathrm{~A}$ and $\mathrm{C})$. PAR-2 protein expression was significantly increased after $10 \mu \mathrm{M}$ NE treatment for $6 \mathrm{~h}$ $(\mathrm{P}<0.05 ; \mathrm{n}=4)$ and $24 \mathrm{~h}(\mathrm{P}<0.05 ; \mathrm{n}=4)$ compared with that in control, but not after $60 \mu \mathrm{M} \mathrm{NE}$ treatment (Fig. 6A and D). However, $120 \mu \mathrm{M}$ NE treatment for $6 \mathrm{~h}$ increased PAR-2 expression $(\mathrm{P}<0.05 ; \mathrm{n}=4)$. There were no statistical significant changes in TRPA1 protein expression when different concentrations of NE were applied to the Caco- 2 cells for the different time periods (Fig. 6A and E).

Immunofluorescence. The present study also evaluated the expression levels of tight junction proteins, in addition to PAR-2 and TRPA1 by immunofluorescence after the application of $10 \mu \mathrm{M} \mathrm{NE}$ for 6 and $24 \mathrm{~h}$. Occludin-positive staining was located on the cell membrane of Caco-2 cells, which was reduced by NE treatment in both 6 and $24 \mathrm{~h}$ groups (Fig. 7A). ZO-1 was also found to be expressed on the surface of Caco-2 cells, where it was found that $6 \mathrm{~h}$ treatment with $\mathrm{NE}$ increased the expression of $\mathrm{ZO}-1$, but $24 \mathrm{~h}$ treatment 

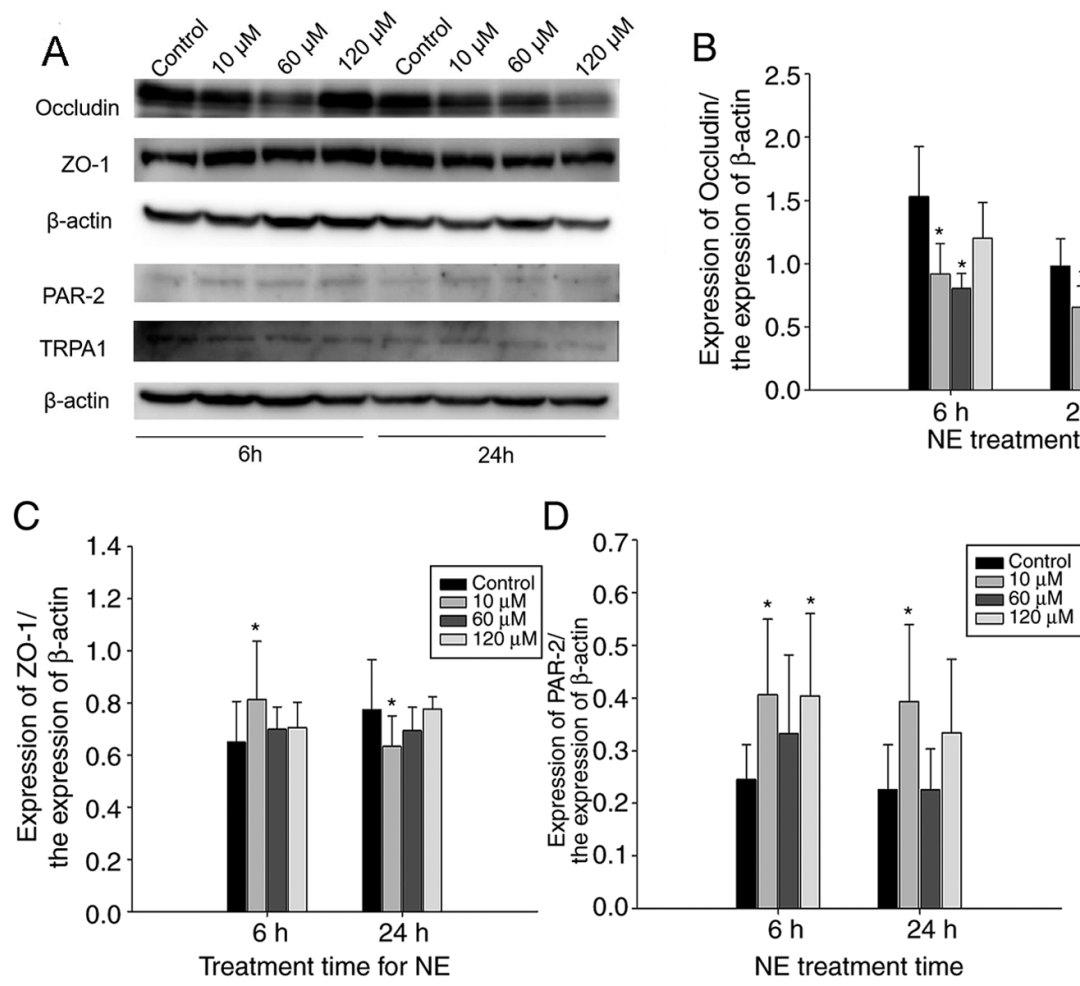

Figure 6. Expression levels of Occludin, ZO-1, PAR-2 and TRPA1 in Caco-2 cells after treatment with NE. (A) Representative western blotting images from four independent experiments. Comparison of the relative expression levels of (B) Occludin, (C) ZO-1, (D) PAR-2 and (E) TRPA1 in colon of control and NE-treated cells. ${ }^{*} \mathrm{P}<0.05$ vs. Control. Data are presented as the mean \pm SD. NE, norepinephrine; ZO-1, zonula occludens-1; PAR-2, protease activated receptor 2; TRPA1, transient receptor potential ankyrin 1 channel.

reduced its expression (Fig. 7B). PAR-2 was observed on the cell membrane, where its staining was stronger in NE-treated $6 \mathrm{~h}$ and $24 \mathrm{~h}$ cells (Fig. 7C). The staining pattern of TRPA1 was different compared with that of the aforementioned proteins (Fig. 7D). The positive staining was discontinuous, which became more obvious after NE treatment for 6 and $24 \mathrm{~h}$. It appeared that TRPA1 gathered on the cell membrane of Caco-2 cells, which was similar with the results observed from immunohistochemistry in the rat colon mucosal epithelium.

\section{Discussion}

In the present study, heat stress induced by heat exposure attenuated body weight gain. Histological examination of the rat colon tissues after heat exposure demonstrated that there was no obvious damage to the rat colonic mucosa, but the protein expression levels of tight junction proteins Occludin and ZO-1 were decreased. These findings were consistent with a previous study, which reported that psychological stress reduced brain and intestinal expression levels of tight junction proteins, including Claudin 5, Occludin, $\alpha$-actin and ZO-1 (1),However, whether elevated NE levels regulated the expression levels of tight junction proteins was not previously investigated (1). The present study observed elevated plasma $\mathrm{NE}$ levels and found that the administration of $10 \mu \mathrm{M}$ NE for 6 and $24 \mathrm{~h}$ downregulated the expression of Occludin in Caco-2 cells, whilst NE treatment upregulated $\mathrm{ZO}-1$ expression after $6 \mathrm{~h}$ treatment but reduced ZO-1 expression after $24 \mathrm{~h}$. These data indicated that NE directly regulated the expression levels of tight junction proteins, which can contribute to altered gut permeability under stress.

In patients with septic shock, NE use is associated with increased enterocyte damage (28), where the reason for this could be the direct regulation by $\mathrm{NE}$ on tight junction proteins. In a previous study on vascular endothelial cells, the inhibitory effect of angiotensin II on Occludin and ZO-1 expression was identified (29). In addition, our unpublished data also revealed the significant inhibitory action of $6 \mathrm{~h} \mathrm{NE}$ treatment on the expression levels of Occludin and ZO-1 in thoracic aortic endothelial cells. Taken together, these findings indicate a direct regulatory effect of this stress hormone on tight junction proteins in epithelial cells. Although there have been a few reports that evaluated the direct regulatory effect of NE on the tight junction proteins $(25,30)$, it has been suggested that in bovine aortic endothelial cells, treatment with NE to concentrations ranging from normal to pathophysiological circulating plasma levels significantly impedes trypan blue dye-bovine serum albumin conjugate diffusion, compared with that in untreated controls (31). The difference between the present study and this previous report in the barrier-modulating effects of NE may be due to the dose and cell type. As a chronic stress hormone, NE promotes tumor progression by stimulating $\beta_{2}$-adrenoreceptors in oral cancer (32). In the present study, treatment of Caco-2 cells with different concentrations of NE for $6 \mathrm{~h}$ did not affect cell viability, but NE increased cell viability $24 \mathrm{~h}$ after treatment. This finding was in accordance with a previous observation that $24 \mathrm{~h}$ NE treatment enhanced cell viability and invasion of pancreatic cancer cells (33). 
A

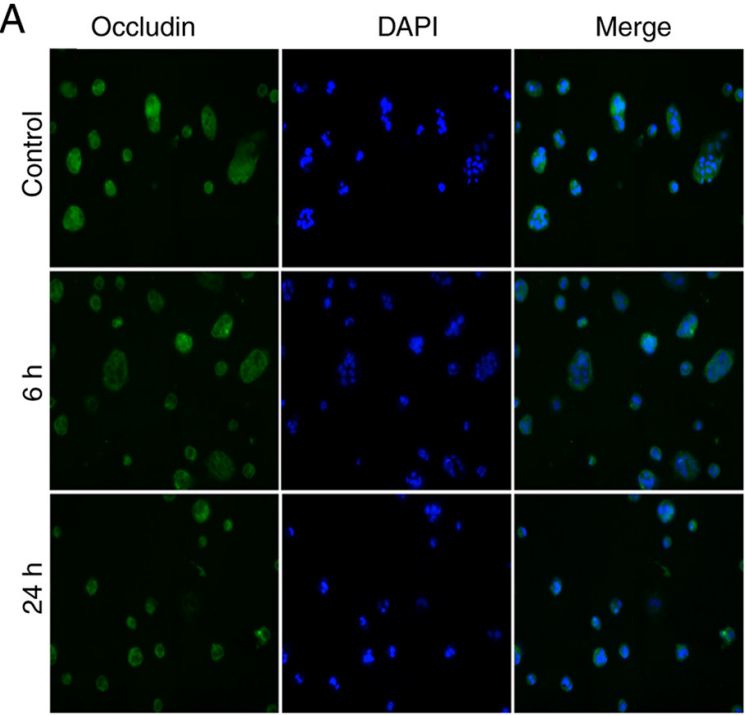

C

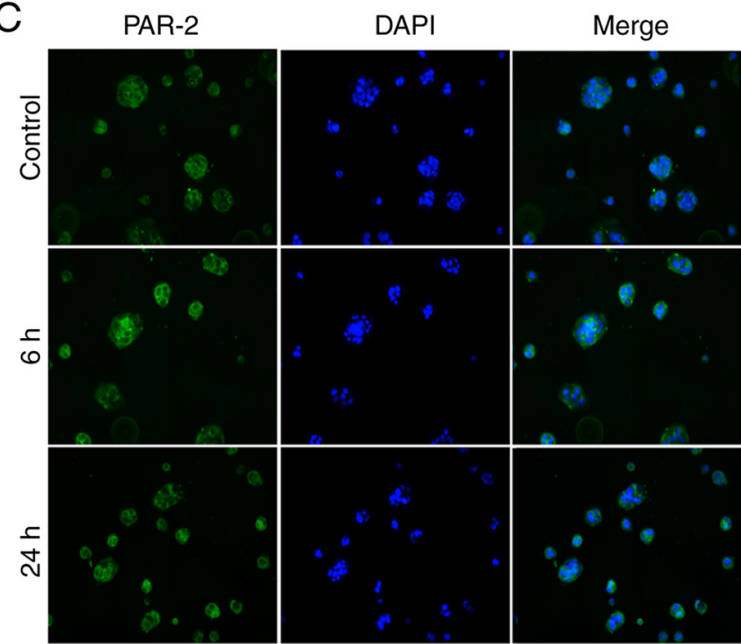

B

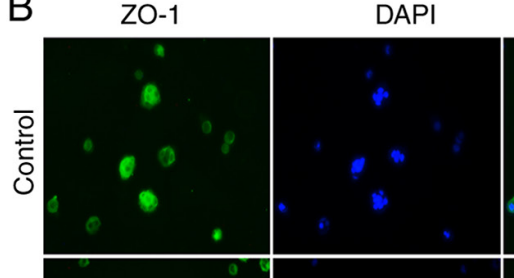

DAPI

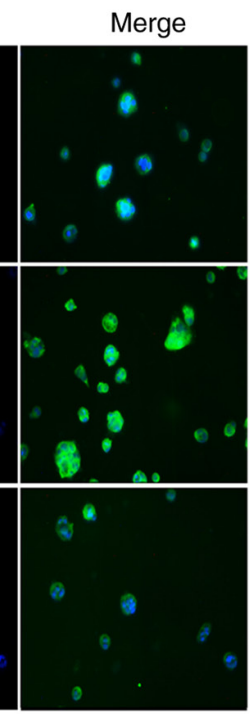

$\mathrm{D}$

D TRPA1

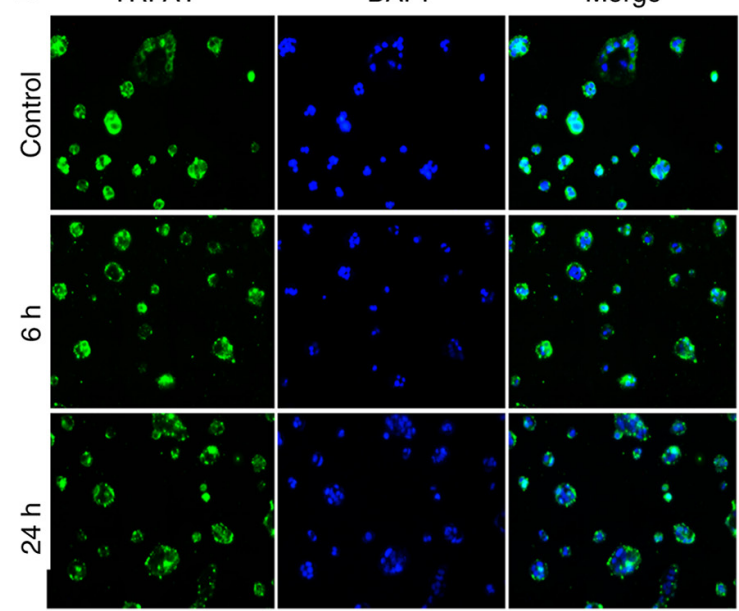

Figure 7. Immunofluorescence staining of Occludin, ZO-1, PAR-2 and TRPA1 in Caco-2 cells after $10 \mu \mathrm{M}$ NE application. Staining of (A) Occludin, (B) ZO-1, (C) PAR-2 and (D) TRPA1. Magnification, x400. NE, norepinephrine; ZO-1, zonula occludens-1; PAR-2, protease-activated receptor 2; TRPA1, transient receptor potential ankyrin 1 channel.

The activation of PAR-2 and mast cell is involved in increased epithelial permeability due to changes in tight junction proteins under heat stress $(11,34,35)$, PAR-2 modulates Ve-Cadherin expression to affect human vascular endothelial barrier function (13), such that activation of PAR2 changes the localization of the tight junction proteins and increases barrier permeability (12). However, it has also been reported that treatment with a PAR-2 agonist prevents the downregulation of tight junction proteins after $P$. aeruginosa elastase treatment in human nasal epithelial cells (36). According to the present study, expression of PAR-2 in colonic epithelial cells was increased after heat exposure, which may be a reason for the altered expression of tight junction proteins in the heat-exposed rats colon. Furthermore, PAR-2 expression was upregulated after application of $10 \mu \mathrm{M}$ NE for both 6 and $24 \mathrm{~h}$, whereas NE level was increased in heat-exposed rats. These findings suggested that NE can regulate the expression of PAR-2 under stress.

TRP channels are non-selective cation channels that act as biosensors for environmental and noxious stimuli, including capsaicin and allicin, in addition to changes in temperature and conditions inside the cell $(14,15)$. The TRPA1 receptor is highly expressed in the intestinal mucosa and can be activated by oxidative stress products, where the cell damage signals can induce oxidative stress (19), which implicates its possible association with intestinal disfunction. Cold stress increases ROS production by TRPA1 activation in A549 cells (37). In addition, upregulation of TRPA1 expression and function on vagal afferents is associated with stress-exaggerated visceral mechanonociception after antral cold $\left(4^{\circ} \mathrm{C}\right)$ stress (38). TRPA1 also mediates cigarette smoke extract-induced damage of bronchial and alveolar epithelial cells via the modulation of oxidative stress, inflammation and mitochondrial damage (39). It has been reported that substance $\mathrm{P}$ may initiate the earliest changes observed in blood-brain barrier permeability (40). In addition, it has also been documented that TRPA1 mediates the development of gastric mucosal and duodenal lesions in a water immersion restraint stress rat model by promoting the release of substance P $(22,41)$. Since TRPA1 is involved in $\mathrm{Ca}^{2+}$ influx and increases in tight junction permeability (42), TRPA1 may contribute to damage in epithelial barrier function by 
regulating oxidative stress induced by stress. The present study demonstrated that the expression of TRPA1 was changed, with increased positive staining observed in the luminal side of the mucosa in heat exposed rats, which was consistent with previous results reported following water avoidance stress (43). Furthermore, the expression pattern was altered after heat exposure and the expression of TRPA1 was concentrated on the luminal surface. The present study investigated the regulatory mechanism mediated by NE on expression of TRPA1. However, there was no change in its protein expression level after treatment with NE for either 6 or for $24 \mathrm{~h}$ (Fig. 6D). It was found that higher levels of TRPA1 were gathered or recruited onto the cell membrane to form dot staining after NE treatment. This may be the reason for the failure in detecting changes in protein expression using western blotting, therefore further investigation is required to confirm the role of $\mathrm{NE}$ on the expression of TRPA1. Furthermore, in the present study, the detailed regulatory mechanisms of $\mathrm{NE}$ on tight junction proteins and PAR-2 function were not investigated. Further experiments are needed to address these questions in the future.

In conclusion, the present study demonstrated the changed expression levels of tight junction proteins, PAR-2 and TRPA after heat exposure, which was implicated in intestinal barrier function under stress. The present results suggested that NE directly regulated the expression of tight junction proteins and PAR-2 in vitro. It was also indicated that NE may be directly responsible for the altered levels of tight junction proteins and PAR-2 under stress.

\section{Acknowledgements}

Not applicable.

\section{Funding}

The present study was supported by National Natural Science Foundation of China (grant nos. 81760265 and 81760055) and Ningxia High School first-class Disciplines (grant no. NXYLXK2017B07; West China first-class Disciplines Basic Medical Sciences at Ningxia Medical University).

\section{Availability of data and materials}

The datasets used and/or analyzed during the current study are available from the corresponding author on reasonable request.

\section{Authors' contributions}

YL contributed to the conception and design of the study and completed the western blotting and immunohistochemistry experiments. HM contributed to cell culture and acquisition of data and performed IF analysis. SN established the animal model. XL performed the Cell Counting Kit- 8 assay. LN contributed to the interpretation of data and revised the article for important intellectual content. GL contributed to the conception and design of the study. YL and GL can authenticate the raw data of this study. All authors read and approved the final version of the manuscript.

\section{Ethics approval and consent to participate}

The experimental procedures were approved by the Animal Ethics Committee of the Ningxia Medical University and Use Committee (Yinchuan, China) and were performed in accordance with the Guidelines of the Council of the Physiological Society of China.

\section{Patient consent for publication}

Not applicable.

\section{Competing interests}

The authors declare that they have no competing interests.

\section{References}

1. Geng S, Yang L, Cheng F, Zhang Z, Li J, Liu W, Li Y, Chen Y, Bao Y, Chen L, et al: Gut microbiota are associated with psychological stress-induced defections in intestinal and blood-brain barriers. Front Microbiol 10: 3067, 2020.

2. Lu S, Wu D, Sun G, Geng F, Shen Y, Tan J, Sun X and Luo Y: Gastroprotective effects of Kangfuxin against water-immersion and restraint stress-induced gastric ulcer in rats: Roles of antioxidation, anti-inflammation, and pro-survival. Pharm Biol 57: 770-777, 2019.

3. Dokladny K, Zuhl MN and Moseley PL: Intestinal epithelial barrier function and tight junction proteins with heat and exercise. J Appl Physiol (1985) 120: 692-701, 2016.

4. Liu B, Shen LJ, Zhao TX, Sun M, Wang JK, Long CL, He DW, Lin T, Wu SD and Wei GH: Automobile exhaust-derived PM2.5 induces blood-testis barrier damage through ROS-MAPK-Nrf2 pathway in sertoli cells of rats. Ecotoxicol Environ Saf 189: $110053,2020$.

5. Elias BC, Suzuki T, Seth A, Giorgianni F, Kale G, Shen L, Turner JR, Naren A, Desiderio DM and Rao R: Phosphorylation of Tyr-398 and Tyr-402 in occludin prevents its interaction with ZO-1 and destabilizes its assembly at the tight junctions. J Biol Chem 284: 1559-1569, 2009.

6. Buckley A and Turner JR: Cell biology of tight junction barrier regulation and mucosal disease. Cold Spring Harb Perspect Biol 10: a029314, 2018.

7. Sunagawa M, Wolf-Johnston A, Nomiya M, Sawada N Andersson KE, Hisamitsu T and Birder LA: Urinary bladder mucosal responses to ischemia. World J Urol 33: 275-280, 2015.

8. Du L, Long Y, Kim JJ, Chen B, Zhu Y and Dai N: Protease activated receptor-2 induces immune activation and visceral hypersensitivity in post-infectious irritable bowel syndrome mice. Dig Dis Sci 64: 729-739, 2019.

9. Lu L, Yan L, Yuan J, Ye Q and Lin J: Shuganyin decoction improves the intestinal barrier function in a rat model of irritable bowel syndrome induced by water-avoidance stress. Chin Med 13: 6, 2018.

10. Kim DH, Cho YJ, Kim JH, Kim YB and Lee KJ: Stress-induced alterations in mast cell numbers and proteinase-activated receptor-2 expression of the colon:Role of corticotrophin-releasing factor. J Korean Med Sci 25: 1330-1335, 2010.

11. Zhong CJ, Wang K, Zhang L, Yang CQ, Zhang K, Zhou SP and Duan LP: Mast cell activation is involved in stress-induced epithelial barrier dysfunction in the esophagus. J Dig Dis 16: 186-196, 2015.

12. Enjoji S, Ohama T and Sato K: Regulation of epithelial cell tight junctions by protease-activated receptor 2. J Vet Med Sci 76: 1225-1229, 2014

13. Zhang R and Ge J: Proteinase-activated receptor-2 modulates Ve-cadherin expression to affect human vascular endothelial barrier function. J Cell Biochem 118: 4587-4593, 2017.

14. Talavera K, Startek JB, Alvarez-Collazo J, Boonen B, Alpizar YA, Sanchez A, Naert R and Nilius B: Mammalian transient receptor potential TRPA1 channels: From structure to disease. Physiol Rev 100: 725-803, 2020.

15. Bamps D, Vriens J, de Hoon J and Voets T: TRP channel cooperation for nociception: Therapeutic opportunities. Annu Rev Pharmacol Toxicol 61: 655-677, 2021. 
16. Taylor-Clark TE, Undem BJ, Macglashan DW Jr, Ghatta S, Carr MJ and McAlexander MA: Prostaglandin-induced activation of nociceptive neurons via direct interaction with transient receptor potential A1 (TRPA1). Mol Pharmacol 73: 274-281, 2008.

17. Gouin O, L'Herondelle K, Lebonvallet N, Gall-Ianotto CL, Sakka M, Buhé V, Plée-Gautier E, Carré JL, Lefeuvre L, Misery L and Le Garrec R: TRPV1 and TRPA1 in cutaneous neurogenic and chronic inflammation: Pro-inflammatory response induced by their activation and their sensitization. Protein Cell 8: 644-661, 2017.

18. Sinica V, Zimova L, Barvikova K, Macikova L, Barvik I and Vlachova V: Human and mouse TRPA1 are heat and cold sensors differentially tuned by voltage. Cells $9: 57,2019$.

19. Viana F: TRPA1 channels: Molecular sentinels of cellular stress and tissue damage. J Physiol 594: 4151-4169, 2016.

20. Wang Y, Yin S, Mei L, Yang Y, Xu S, He X, Wang M, Li M, Zhang $\mathrm{Z}$ and $\mathrm{He} \mathrm{Q}$ : A dual receptors-targeting and size-switchable 'cluster bomb' co-loading chemotherapeutic and transient receptor potential ankyrin 1 (TRPA-1) inhibitor for treatment of triple negative breast cancer. J Control Release 321: 71-83, 2020.

21. Pires PW and Earley S: Neuroprotective effects of TRPA1 channels in the cerebral endothelium following ischemic stroke. Elife 7: e35316, 2018.

22. Xu Y, Huang C, Deng HI, Jia J, Wu Y, Yang J and Tu W: TRPA1 and substance $\mathrm{P}$ mediate stress induced duodenal lesions in water immersion restraint stress rat model. Turk J Gastroenterol 29 : 692-700, 2018

23. Morris LS, McCall JG, Charney DS and Murrough JW: The role of the locus coeruleus in the generation of pathological anxiety. Brain Neurosci Adv 4: $2398212820930321,2020$.

24. Sawka MN, Leon LR, Montain SJ and Sonna LA: Integrated physiological mechanisms of exercise performance, adaptation, and maladaptation to heat stress. Compr Physiol 1: 1883-1928, 2011.

25. Kalinin S, Feinstein DL, Xu HL, Huesa G, Pelligrino DA and Galea E: Degeneration of noradrenergic fibres from the locus coeruleus causes tight-junction disorganisation in the rat brain. Eur J Neurosci 24: 3393-3400, 2006.

26. Aroori SV, Cogan TA and Humphrey TJ: Effect of noradrenaline on the virulence properties of campylobacter species. Int J Microbiol 2014: 279075, 2014.

27. Zong Y,Zhu S, Zhang S, Zheng G, Wiley JW and Hong S: Chronic stress and intestinal permeability: Lubiprostone regulates glucocorticoid receptor-mediated changes in colon epithelial tight junction proteins, barrier function, and visceral pain in the rodent and human. Neurogastroenterol Motil 31: e13477, 2019.

28. Habes Q, van Ede L, Gerretsen J, Kox M and Pickkers P. Norepinephrine contributes to enterocyte damage in septic shock patients: A prospective cohort study. Shock 49: 137-143, 2018.

29. Zhang W, Yang H, Zhu L, Luo Y, Nie L and Li G: Role of EGFR/ErbB2 and PI3K/AKT/e-NOS in lycium barbarum polysaccharides ameliorating endothelial dysfunction induced by oxidative stress. Am J Chin Med 47: 1523-1539, 2019.

30. Liu J,Zheng M,Zhao X,Zha YJ, Li HN and Huang GQ: Effects of vasoactive drugs on hepatic and intestinal circulation and intestinal barrier in patients with septic shock. J Investig Med: Jan 13, 2021 (Epub ahead of print). doi: 10.1136/jim-2020-001685.
31. Bottaro D, Shepro D, Peterson S and Hechtman HB: Serotonin norepinephrine, and histamine mediation of endothelial cell barrier function in vitro. J Cell Physiol 128: 189-194, 1986.

32. Zhang B, Wu C, Chen W, Qiu L, Li S, Wang T, Xie H, Li Y, Li C and Li L: The stress hormone norepinephrine promotes tumor progression through beta2-adrenoreceptors in oral cancer. Arch Oral Biol 113: 104712, 2020.

33. Qian W, Lv S, Li J, Chen K, Jiang Z, Cheng L, Zhou C, Yan B, Cao J, Ma Q and Duan W: Norepinephrine enhances cell viability and invasion, and inhibits apoptosis of pancreatic cancer cells in a Notch1dependent manner. Oncol Rep 40: 3015-3023, 2018.

34. Jin H, Li Z, Guo X, Tong H, Liu Z, Chen Y, Su L and Huang Q: Microcirculatory disorders and protective role of antioxidant in severe heat stroke: A rat study. Shock 46: 688-695, 2016.

35. Shivers RR, Pollock M, Bowman PD and Atkinson BG: The effect of heat shock on primary cultures of brain capillary endothelium: Inhibition of assembly of zonulae occludentes and the synthesis of heat-shock proteins. Eur J Cell Biol 46: 181-195, 1988.

36. Nomura K, Obata K, Keira T, Miyata R, Hirakawa S, Takano KI, Kohno T, Sawada N, Himi T and Kojima T: Pseudomonas aeruginosa elastase causes transient disruption of tight junctions and downregulation of PAR-2 in human nasal epithelial cells. Respir Res 15: 21, 2014.

37. Sun W, Wang Z, Cao J, Cui H and Ma Z: Cold stress increases reactive oxygen species formation via TRPA1 activation in A549 cells. Cell Stress Chaperones 21: 367-372, 2016.

38. Chen X, Luo Q, Yan X, Li W and Chen S: Vagal transient receptor potential ankyrin 1 mediates stress-exacerbated visceral mechanonociception after antral cold exposure. J Neurogastroenterol Motil 25: 442-460, 2019.

39. Wang M, Zhang Y, Xu M, Zhang H, Chen Y, Chung KF, Adcock IM and Li F: Roles of TRPA1 and TRPV1 in cigarette smoke-induced airway epithelial cell injury model. Free Radic Biol Med 134: 229-238, 2019

40. Corrigan F, Mander KA, Leonard AV and Vink R: Neurogenic inflammation after traumatic brain injury and its potentiation of classical inflammation. J Neuroinflammation 13: 264, 2016.

41. Xu Y, Jia J, Xie C, Wu Y and Tu W: Transient receptor potential ankyrin 1 and substance $\mathrm{P}$ mediate the development of gastric mucosal lesions in a water immersion restraint stress rat model. Digestion 97: 228-239, 2018.

42. Kanda Y, Yamasaki Y, Sasaki-Yamaguchi Y, Ida-Koga N, Kamisuki S, Sugawara T, Nagumo $Y$ and Usui T: TRPA1-dependent reversible opening of tight junction by natural compounds with an $\alpha, \beta$-unsaturated moiety and capsaicin. Sci Rep 8: 2251, 2018.

43. Pierce AN, Di Silvestro ER, Eller OC, Wang R, Ryals JM and Christianson JA: Urinary bladder hypersensitivity and dysfunction in female mice following early life and adult stress. Brain Res 1639: 58-73, 2016.

This work is licensed under a Creative Commons Attribution-NonCommercial-NoDerivatives 4.0 International (CC BY-NC-ND 4.0) License. 